\title{
30 Jahre Politikversagen: Deutschland mit zwei Seelen
}

Im November 2019 feiert Deutschland „30 Jahre Mauerfall“. Die Stimmung ist dennoch düster: Heute betrachtet sich über ein Drittel der Ostdeutschen als Bürger zweiter Klasse - wie aus einer Umfrage des Allensbach Instituts für Demoskopie hervorgeht. Der Konvergenzprozess zwischen östlichem und westlichem Deutschland ist zum Stillstand gekommen und scheint sich umzukehren. Ostdeutsche wählen heute anders, denken anders und fühlen anders. Deutschland ist ein Land mit zwei Seelen. Am 1. September 2019 hat bei den Landtagswahlen in den neuen Bundesländern Sachsen und Brandenburg die Alternative für Deutschland (AfD) 27,5\% bzw. 23,5\% der Stimmen bekommen. In Westdeutschland erhält die AfD nicht einmal halb so viele Stimmen. Es ist jetzt klar, dass entgegen den Erwartungen der Osten nicht wie der Westen wurde. Stattdessen dominieren in Ostdeutschland Frustration und Enttäuschung.

Was ist schief gelaufen? Haben wirtschaftliche Faktoren zu dieser Situation beigetragen? Ein Blick auf die Daten stützt diese Ansicht. Das Pro-Kopf-Einkommen in Ostdeutschland wuchs zwischen 1991 und 1996 schneller als in Westdeutschland. Das Bruttoinlandsprodukt (BIP) pro Kopf stieg von $42 \%$ des BIP in Westdeutschland auf $67 \%$. In den folgenden 20 Jahren blieb das relative Pro-Kopf-BIP in Ostdeutschland jedoch nahezu unverändert und stieg nur auf $73 \%$ wie im Jahresbericht der Bundesregierung zum Stand der Deutschen Einheit 2018 zu lesen ist. So kam der Prozess der wirtschaftlichen Konvergenz zwischen Ost und West bereits vor rund 25 Jahren zum Erliegen. Die geringe Konvergenz seit 1996 von $67 \%$ auf $73 \%$ des westdeutschen Pro-Kopf-Einkommens erklärt sich aus Lohnzuwächsen im öffentlichen Sektor in Ostdeutschland sowie der Abwanderung von Arbeitskräften in das westliche Deutschland, die das ostdeutsche Pro-Kopf-Einkommen erhöht haben.

Entsprechend der Wachstumstheorie wachsen ärmere Regionen rascher als reiche Regionen, wodurch es zur Konvergenz der Pro-Kopf-Einkommenniveaus kommt. Ein Vergleich Ostdeutschlands mit osteuropäischen Ländern zeigt das relativ schlechte Abschneiden Ostdeutschlands deutlich. Laut einer Studie der Europäischen Zentralbank haben Slowenien, die Slowakei und die Tschechische Republik bereits 2008 $80 \%$ bis $90 \%$ des EU28-Pro-Kopf-Einkommens (in Kaufkraftparitäten umgerechnet) erreicht. Die Städte Warschau, Prag und Bratislava haben bereits 2008 das Pro-KopfEinkommensniveau Wiens (Berlins Pro-Kopf-Einkommen liegt darunter) überschritten. Ostdeutschland liegt 2017 bei etwas über $70 \%$ des westdeutschen Pro-Kopf-Einkommensniveaus. Das ist wahrlich bescheiden angesichts der massiven Transferzahlungen aus Westdeutschland, die die anderen osteuropäischen Länder nicht erhalten haben.

Welches Ereignis hat den Konvergenzprozess in Ostdeutschland zum Stillstand gebracht? Um zu verstehen, was passiert ist, müssen wir uns den nach dem Mauerfall eingeleiteten politischen Reformen zuwenden. Die Bundesregierung beschloss im Juli 1990, den Handel mit Ostdeutschland über Nacht zu liberalisieren und alle bestehenden Hemmnisse für Kapital- und Arbeitsströme zu beseitigen. Die Umtauschrate zwischen der ostdeutschen Mark und der Deutschen Mark wurde für kleinere Beträge auf 1:1 und für größere Summen auf 2:1 festgelegt. Durch diese Währungsreform stiegen die Löhne im Osten unmittelbar auf $55 \%$ des westdeutschen Niveaus, obwohl die Produktivität im Osten 1991 nur $34 \%$ des westlichen Produktivitätsniveaus betrug. Bereits 1994 hatten die Ostlöhne $70 \%$ der Westlöhne erreicht. Das ostdeutsche Verarbeitende Gewerbe ging über Nacht Bankrott und Ostdeutschlands frühere erfolgreiche Exportmärkte in Osteuropa verschwanden.

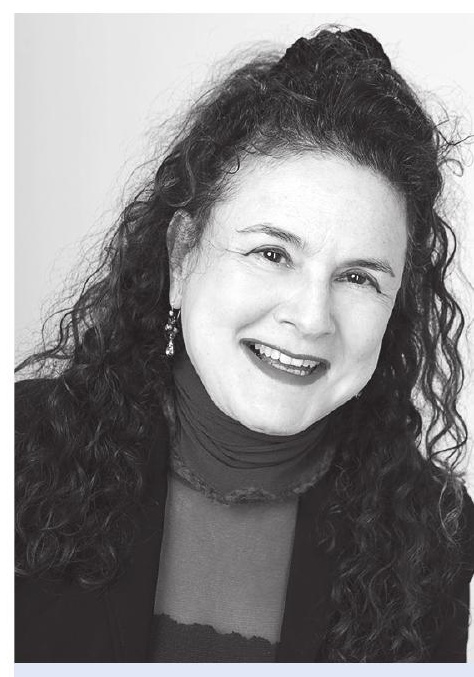

Dalia Marin ist Professorin an der TUM School of Management der Technischen Universität München. 
Im März 1990 beschloss die ostdeutsche Regierung, eine neue Superbehörde - die Treuhandanstalt - zu gründen. Die Treuhandanstalt hat die ostdeutschen Firmen und Vermögenswerte privatisiert und an westliche Firmen verkauft, oft zu einem symbolischen Preis von 1 DM im Austausch für Arbeitsplatzgarantien. Diese massive Subvention schuf einen Anreiz für westdeutsche Firmen in den Osten zu ziehen, obwohl das Land seinen komparativen Vorteil der niedrigen Löhne durch die Währungsreform eingebüßt hatte. Das Programm funktionierte, und 1994 hatte die Treuhand alle ostdeutschen Firmen an westdeutsche Firmen verkauft. Zunächst wuchs die ostdeutsche Wirtschaft rasant und holte die westdeutsche Wirtschaft ein. Nach getaner Arbeit wurde die Treuhandanstalt 1994 abgewickelt und in die Bundesanstalt für vereinigungsbedingte Sonderaufgaben überführt. Ohne den Zuschuss der Treuhand fanden westliche Firmen jedoch in Ostdeutschland keinen attraktiven Investitionsstandort mehr. Mit dem Austrocknen der Investitionen aus Westdeutschland und jener aus dem Ausland kam der Konvergenzprozess zum Stillstand.

Die Ostdeutschen mochten die Treuhandanstalt nicht. Ostdeutschland sah in der Treuhand die Institution, die alle wertvollen Vermögenswerte Ostdeutschlands an westliche Firmen verschenkte. Noch heute machen die Linke und die AfD die Treuhand für das Elend der ostdeutschen Wirtschaft verantwortlich wie in einem Beitrag der Zeitung „Die Welt“ vom 7. Mai 2019 veranschaulicht wird. Damals in den 1990er Jahren wurden die Gründung der Treuhand und die von ihr eingeleiteten Maßnahmen vor den Ostdeutschen damit gerechtfertigt, dass Ostdeutschland „nichts zu verkaufen“ habe und wegen der geringen Qualität seiner Produkte keine Alternative zur Privatisierung bestehe.

Dieses Narrativ verstößt jedoch gegen das ökonomische Gesetz des komparativen Vorteils. Ein Land hat immer etwas zu verkaufen, wenn Löhne und Preise niedrig genug sind. Die durch die Währungsreform eingeführten hohen Löhne und Preise verhinderten jedoch das Gedeihen der ostdeutschen Wirtschaft, das in anderen osteuropäischen Ländern nach dem Zusammenbruch des Kommunismus gelang. Das Narrativ, dass Ostdeutschland „nichts zu verkaufen“ hätte und ein „Verarbeitendes Gewerbe mit geringem Wert" besitze, wirkte sich verheerend auf die ostdeutsche Befindlichkeit aus. Die Ostdeutschen fühlten sich „wertlos“ in der Marktwirtschaft.

Der Hauptfehler bestand jedoch darin, dass die Regierung die Treuhandanstalt auflöste, nachdem alle Vermögenswerte des Ostens verkauft waren. Dies brachte den ökonomischen Konvergenzprozess ins Stocken. Ohne Subventionen war der ostdeutsche Standort nicht mehr attraktiv für westdeutsche und ausländische Firmen. Das erklärt auch, warum sich bis heute keine Großunternehmen in Ostdeutschland angesiedelt haben. Die Treuhand hätte ihre Arbeit fortsetzen und sich zu einer Institution entwickeln sollen, die westdeutsches und ausländisches Kapital anzieht, indem sie Subventionen und Steueranreize an Unternehmen verteilt, die bereit sind, trotz hoher Löhne, die über der Produktivität liegen, zu investieren.

Es ist nie zu spät. Die Bundesregierung diskutiert derzeit, wie in Ostdeutschland „gleichwertige Lebensverhältnisse“ geschaffen werden können. Um dieses Ziel zu erreichen, sollte die Bundesregierung eine neue Institution schaffen, die wirtschaftliche Anreize für westdeutsches und ausländisches Kapital bereitstellt, um Ostdeutschland die Chance zu geben, sich im Sinne des Kanzlers der deutschen Einheit, Helmut Kohl, in eine blühende Landschaft zu verwandeln. Darüber hinaus würde eine wirtschaftliche Erholung Ostdeutschlands nicht nur materielle Vorteile bringen. Sie könnte auch dazu beitragen, die psychologische Spaltung Deutschlands zu heilen und damit die Tendenz der Ostdeutschen, extremistische Parteien zu wählen, die von 